\title{
Unlove the bomb
}

Q. J. Econ. https://doi.org/10.1093/aje/ajx037

(2017)

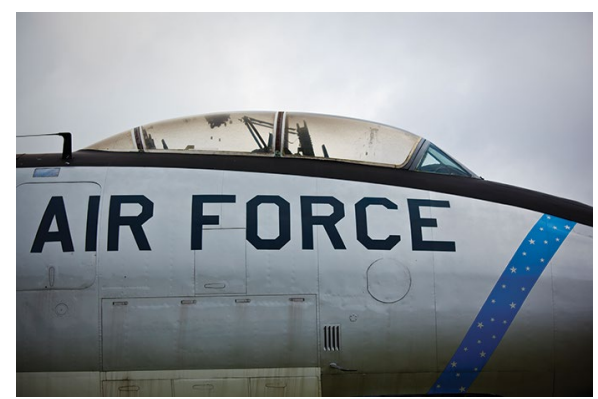

Credit: Fluxfoto/E+/Getty Images

Interventions in other countries can take a variety of forms: from diplomacy to overwhelming military force. Putting the legitimacy of foreign interventionism aside, a key question is how effective different types of intervention are, especially when loss of civilian life is involved.

Melissa Dell and Pablo Querubin examine the effectiveness of US firepower strategies in the Vietnam War. By comparing otherwise similar hamlets that were either air-strike targets or not, they find that bombing had the opposite effect than that intended: it strengthened support for the Viet Cong, increased the likelihood of Viet Cong counter-attacks, and weakened local government. The US Army and the US Marine Corps took different approaches towards counterinsurgency in Vietnam: the army relied on overwhelming firepower, whereas the marines focused on winning hearts and minds. By comparing hamlets commanded by the army with nearby hamlets commanded by the marines, Dell and Querubin find that the marines' approach of providing development aid and collaborating closely with local security forces was associated with better outcomes and more positive attitudes towards the United States and the South Vietnamese government.

The implications of Dell and Querubin's findings are of current relevance: air-strike precision has improved, but still involves significant loss of civilian life. Their research suggests that politicians and pundits who argue for firepower-based military interventions ought to think again.

Stavroula Kousta

Published online: 5 October 2017

DOI: 10.1038/s41562-017-0230-2 